Volumen: 30 Fecha de recibido: 12/2/2020

Año: 2020

Fecha de aceptado: 5/3/2020

Numero: 2
Número de páginas: 42-59
Fecha de publicación: Julio-Diciembre de 2020

Correo: revista.sciencia@up.ac.pa

URL: https://revistas.up.ac.pa/index.php/scientia

\title{
ESTUDIO ETNOBOTÁNICO DE DOS COMUNIDADES EMBERÁ DEL RÍO GATÚN, PANAMÁ
}

\author{
Leidy Carballo ${ }^{1}$, Francisco Farnum Castro ${ }^{2}$ y Vielka Murillo Godoy ${ }^{3}$ \\ ${ }^{1}$ Universidad de Panamá. Panamá, Panamá \\ thalimangari@gmail.com \\ 2 Universidad de Panamá, Panamá, Panamá \\ frank0523@hotmail.com ORCID: https://orcid.org/0000-0002-5879-2296. \\ ${ }^{3}$ Universidad de Panamá, Panamá, Panamá \\ vielkam@gmail.com ORCID: https://orcid.org/0000-0002-6284-4466
}

\section{RESUMEN}

En este trabajo se registran las especies vegetales relacionadas con el conocimiento cultural de dos comunidades indígenas de la etnia Emberá del Río Gatún (San Juan de Pequení, La Bonga y Emberá Cimarrones). El tema se abordó desde la perspectiva etnobotánica, destacando la presencia y el papel de las plantas accesibles en las zonas. En tal sentido, se resaltan aspectos de interés propios de la etnobotánica como son la nomenclatura científica y vernácula de las especies, los usos, las formas de forma de preparación, así como el flujo y persistencia de la información entre generaciones de los moradores. Se registró información para 81 especies vegetales todas con usos conocidos, las familias más nombradas fueron: Arecaceae, Anacardiaceae, Malvaceae y Rubiaceae. Mediante encuestas y entrevistas (personas clave), se identificaron 206 usos de las especies, distribuidos en 7 categorías etnobotánicas siendo la medicinal (48) y la comestible (41) las categorías mayormente mencionadas. El estudio demuestra que los Emberá son un grupo fuertemente ligado a la naturaleza y sus necesidades vitales están sustentadas por el recurso vegetal, situación que les permite ser conscientes de la conservación y manejo sostenible de los bosques que los rodean.

Palabras clave: conocimiento tradicional, medicina alternativa, valor de uso, Cuenca del Canal de Panamá.

\section{ETHOBOTANICAL STUDY OF TWO EMBERA COMMUNITIES OF THE GATUN RIVER}

\section{ABSTRACT}

In this work, the plant species related to the cultural knowledge of two indigenous communities of the Emberá ethnic group of the Gatún River (San Juan de Pequení, La Bonga and Emberá Cimarrones) are registered. The subject was approached from the ethnobotanical perspective, highlighting the presence and role of accessible plants in the zones. In this sense, aspects of interest inherent to ethnobotany are highlighted, such as the scientific and vernacular nomenclature of the species, the uses, the forms of preparation, as well as the flow and persistence of information between generations of the inhabitants. Information was recorded for 81 plant species, all with known uses; the most named 
families were: Arecaceae, Anacardiaceae, Malvaceae and Rubiaceae. Through surveys and interviews (key people), 206 uses of the species were identified, distributed in 7 ethnobotanical categories, being medicinal (48) and edible (41) the most mentioned categories. The study shows that the Emberá are a group strongly linked to nature and their vital needs are supported by plant resources, a situation that allows them to be aware of the conservation and sustainable management of the forests that surround them.

KEYWORDS: Traditional Knowledge, Alternative Medicine, Use Value, Panama Canal Basin.

\section{INTRODUCCIÓN}

Desde 1850 en Panamá han disminuido las áreas de bosques a gran velocidad. Se estima que en ese año los bosques abarcaban el 91\% del país. Entre 1947 y 1970 la cobertura boscosa se redujo de 70\% a 53\%. Para el año 2000 la superficie boscosa alcanzaba apenas el $45 \%$ total del país, o sea la mitad de la cobertura de hace 150 años. (Tossi, 1971). La mayoría de los bosques primarios de Panamá están amenazados, y junto con ellos el rico patrimonio natural que contienen los territorios y el sustento de los pueblos indígenas. (FAO-CATIE, 2000; Farnum y Murillo, 2014).

En materia de medio ambiente, el concepto de conservación se emplea para referirse al cuidado y protección de todo aquello que involucra el medio ambiente natural, tal es el caso de los animales, las plantas y el entorno natural en general. En tanto, la conservación consiste en que los seres humanos, los mayores responsables del daño al medio ambiente, promovamos y contribuyamos con nuestras acciones a evitar la contaminación y asimismo el uso indiscriminado y no responsable de recursos no renovables. (Ucha, 2013).

Los pueblos indígenas se sienten conectados con la naturaleza y se sienten parte del sistema en el que viven. Los recursos naturales son considerados como una propiedad compartida y son respetados como tal. Mediante la protección de los recursos naturales, como los bosques y ríos, muchas comunidades indígenas ayudan a mitigar los efectos del cambio climático. (Moreno, 2009).

Sus formas y medios de vida pueden enseñarnos mucho sobre la conservación de los recursos naturales, el cultivo sostenible de alimentos y la vida en armonía con la naturaleza. Reavivar estos conocimientos que tienen su origen en un patrimonio y legado histórico es esencial para hacer frente a los retos a los que se enfrentan la alimentación y la agricultura hoy en día y en el futuro. (Farnum, 2014).

Estos pueblos indígenas han adaptado sus formas de vida para adaptarse y respetar su medio ambiente. En las montañas, los sistemas creados por los pueblos indígenas conservan el suelo, reducen la erosión, conservan el agua y logran reducir el riesgo de desastres. En los pastizales, las comunidades de pastores indígenas gestionan el pastoreo de ganado y el cultivo de forma sostenible para que las praderas preserven su biodiversidad. En la Amazonia, los ecosistemas mejoran cuando los indígenas los habitan. (Rivas, 2015).

Su relación con la madre tierra les obliga a conservar el medio ambiente para la supervivencia de las generaciones del presente y el futuro, asumiendo un rol de guardianes con derechos y responsabilidades, que defienden y garantizan la protección, disponibilidad y pureza, por ejemplo, del agua, tal como se establece en la declaración de Kioto de los pueblos indígenas sobre el agua del 2003. (Catrin, 2015). 
La etnobotánica es una rama de la Botánica encargada de estudiar cómo se relacionan los seres humanos con las plantas de su entorno, desde sus inicios el ser humano siempre ha estado en contacto con las plantas, el ser humano siempre ha tenido una dependencia muy fuerte con las plantas tanto como para fines alimenticios y medicinales, hasta nuestros días ese nexo con la naturaleza se mantiene, aunque hay grupos étnicos que tratan dentro de lo posible de no perder esa interacción, es lo que sucede con los diferentes grupos indígenas a nivel mundial.

Los Emberá son parte del grupo indígena más importante del país. Son muy respetuosos con la naturaleza y trabajan por conservar las condiciones del territorio en que habitan. Los Emberá practican la agricultura, la cacería y la pesca; comercian con el plátano y el maíz, pero en las últimas décadas la actividad turística incrementó la demanda de artesanías, que son compradas directamente por los turistas y en otros casos, por intermediarios. Además, basan su economía en la construcción de canoas, cultivos de la caña de azúcar, arroz, yuca, frijol, piña, aguacate y cítricos. (Jansasoy, 2019).

Los bosques tropicales son espacios donde habitan muchos pueblos indígenas, entre ellos los Emberá. Según un estudio financiado por la Unión Europea en 1992, en las zonas de bosque tropical aproximadamente 2 millones de indígenas, cuyos sistema alimentario y seguridad alimentaria dependen de los ecosistemas boscosos, los cuales proporcionan fuentes y medios de superviviencia. De acuerdo a David Kaimowitz, director general del centro de Investigación Forestal Internacional (CIFOR):

"Cien millones de personas dependen de los bosques para obtener los elementos básicos para su supervivencia, tanto bienes y servicios como ingresos. Al menos una tercera parte de la población rural del mundo depende de la leña, plantas medicinales, alimentos y abono orgánico para la agricultura que provienen de los bosques. Los bosques son también una fuente fundamental de ingresos para extensas poblaciones de habitantes rurales pobres en particular de África y Asia y en menor medida de América Latina ",

donde los pueblos indígenas no son la excepción.

El pueblo indígena Emberá está distribuido entre Colombia, Panamá y Ecuador. Son originarios del Chocó colombiano, ingresan a Panamá a finales del siglo XVII y principios del XVIII, ocupando el territorio que iban dejando los Kunas debido al enfrentamiento. Se ubicaron en la vertiente del Pacífico del Darién, en los márgenes de los ríos Jaqué, Sambú y Balsas, y posteriormente se extendieron por la Cuenca de los ríos Chucunaque y Tuira. Proceden también de otras tribus migratorias que vinieron después de la conquista y poblaron la región meridional en Darién y de las mezclas de los indios panameños de esa región y los Caucanos de Colombia. Los Emberá están localizados al Oriente del país, principalmente en la Comarca Emberá y en tierras colectivas, como comunidades dispersas en la provincia de Darién, en especial en los distritos de Chepigana y Pinogana, hasta las cercanías de Colombia y en el Este de la provincia de Panamá.

En 1983 el gobierno panameño creó, mediante la Ley 22, la Comarca Emberá Wounaan. La Comarca está dividida en dos áreas, colindando con la provincia del Darién y el Parque Nacional Darién. En Panamá la gran mayoría de los emberá viven en la Comarca Emberá Wounaan y la provincia de Darién. También hay algunas poblaciones cerca del Lago Bayano en la provincia de Panamá y cerca del Canal 
(en las provincias de Panamá y Colón). Hay poblaciones significativas de emberás en la ciudad de Panamá y sus áreas suburbanas. En el este del país las poblaciones emberá dentro de la Comarca están representadas por el Congreso General Emberá -Wounaan y las que se encuentran fuera de la Comarca por el Congreso General de Tierras Colectivas Emberá - Wounaan.

A pesar de la gran diversidad vegetal existente en Panamá, se han realizado muy pocos estudios etnobotánicos con los indígenas Emberá, esto debido a que en su mayoría viven en áreas de difícil acesso.

Uno de los primeros en hacer estudios etnobotánicos con los Emberá es James Duke, cuyo aporte valioso de sus estudios es la publicación del Diccionario Etnobotánico de Darién (1968) en donde menciona el nombre científico de las plantas, nombre en lengua emberá, el uso de la planta y la forma en que se preparan las mismas. Este estudio es un estudio base en la etnobotánica de los grupos emberá de Panamá.

Por otro lado Runk (2001) realiza un estudio sobre el uso de la palma Astrocaryum standleyanum para cestería por artesanos Wounaan y Emberá en la provincia de Darién, Panamá. Las fibras de la palma son una fuente tradicional de material para canastas, las cuales han llegado a ser objetos de arte comercial en los últimos quince años. La venta de canastas de $A$. standleyanum es una fuente importante de ingresos de efectivo, con ventas domésticas e internacionales.

Arango e Iságama (2012) en la región de Antioquia, Colombia han realizado estudios que aportan al conocimiento del uso de algunas plantas en el carácter etnoodontológico dado por los emberá para los problemas dentales y para la prevención de enfermedades periodontales, indagando acerca de esos conocimientos tradicionales, la identificación de las plantas y las partes utilizadas y las formas de preparación, con el fin de que más adelante se busque la viabilidad de que estos saberes puedan integrar estrategias que posibiliten un acercamiento de tipo intercultural entre la institucionalidad y las comunidades indígenas, que debe encararse como un reto que impone nuevas miradas y reconocimiento del saber tradicional, en diálogo con el conocimiento formal o científico.

Como mucho de este saber tradicional se está perdiendo, el objetivo de este estudio es recopilar información valiosa de las plantas medicinales y otros usos que los indígenas Emberá (San Juan de Pequení y Gatún) le dan a las plantas de su entorno, estudio que nos lleva a comprender la necesidad de conservar estas áreas boscosas que están inmersas en parques nacionales que tienen mucha influencia con el recurso acuático del Canal de Panamá.

\section{Materiales y Métodos}

\section{ÁREA DE ESTUDIO}

El estudio se realizó en dos comunidades del Río Gatún: San Juan de Pequení, Comunidad La Bonga (Parque Nacional Chagres) y la Comunidad Emberá Cimarrones, Gatún (Parque Nacional Soberanía) Provincia de Colón, República de Panamá. Figura 1.

El área de San Juan de Pequení, La Bonga, ubicada a orillas del río Pequení ( $9^{\circ} 22^{\prime} 50.8^{\prime \prime} \mathrm{N}, 79^{\circ} 31^{\prime}$ 31.6" O ), al cual se accede por el Lago Alajuela hasta el río Pequení, es un área de intervención media y con procesos activos de colonización que están expandiendo las áreas agrícolas, transformando las 
coberturas boscosas originales. Su población, de unos 169 habitantes, está conformada por Emberás que migraron de la provincia de Darién, Panamá. (INEC, 2010).

El área de Emberá Cimarrones, Gatún se encuentra en el Corregimiento de Limón en la Provincia de Colón, Panamá $\left(9^{\circ} 15^{\prime} 00^{\prime \prime}, \mathrm{N} 79^{\circ} 49^{\prime} 00^{\prime \prime} 0 / 9^{\circ} .25^{\prime} \mathrm{N}, 79^{\circ} .81^{\prime} 67^{\prime \prime} \mathrm{O}\right)$, al cual se accede por el Lago Gatún, es un área en buen estado de conservación. Su población, de unos 63 habitantes, está conformada por Emberás que también migraron de la provincia de Darién, Panamá. (INEC, 2010).

Los bosques de ambas áreas de estudios son bosques húmedos tropicales con una precipitación de aproximadamente $2500 \mathrm{~mm}$, con una época seca que va de enero a abril y una época lluviosa de mayo a noviembre, la temperatura promedio de $26^{\circ} \mathrm{C}$ y una humedad relativa de $92 \%$.

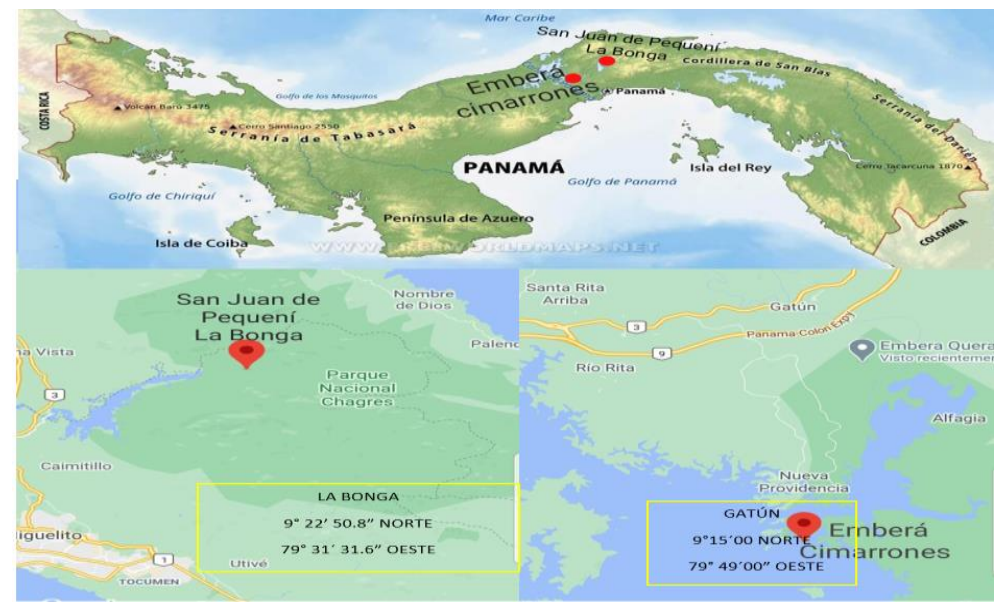

Figura 1. Ubicación de las áreas de estudio.

Los trabajos de campo se realizaron entre agosto de 2018 y septiembre de 2019. Para la caracterización de los usos de las platas se llevaron a cabo entrevistas abiertas con pobladores que fueran residentes permanentes en el área de estudio (ancianos-personas clave). Se realizaron registros etnográficos para detectar los informantes mejor calificados en el tema, los rasgos socioculturales, así como los procesos de abandono y persistencia de hábitos de uso relacionados con las plantas. El total de los entrevistados ascendió a 96, compuesto por 26 mujeres, 34 varones, 22 jóvenes y 14 ancianos. Paralelo a las entrevistas se realizaron encuestas semiestructuradas en forma aleatoria y proporcional a las poblaciones rural y urbana con el fin de registrar las categorías de uso y el flujo de información generacional.

La identificación taxonómica de las plantas se realizó en campo con ayuda de los especialistas taxonomistas mediante el uso de bibliografía especializada como el Catálogo de Plantas Vasculares de Panamá y comparación de muestras en el Herbario de la Universidad de Panamá (PMA). La verificación y actualización de los nombres científicos se realizó con apoyo del Catálogo de las Plantas Vasculares de Panamá (Correa et al., 2004), The International Plant Index (IPNI) y la base datos Tropicos del Missouri Botanical Garden.

\section{Determinación de usos de las plantas}


Para determinar los usos culturales de las plantas se realizaron entrevistas (encuestas) a miembros claves (ancianos) de las comunidades, las personas entrevistadas dieron información de las plantas: nombre común, parte de la planta utilizada, enfermedad a la que se asocia la planta, otros usos ( alimenticios, vivienda, artesanía, maderables, entre otros). Para el análisis de los resultados se utilizó el índice de valor de uso (IVU).

Para conocer la importancia del uso de las plantas por los moradores de la comunidad La Bonga y Gatún, se utilizó el Índice de Valor de Uso (IVU). Por eso se utilizó el Índice de Frecuencia Relativa de Cox (1980) para obtener un valor de uso para cada especie, que indicará la importancia cualitativa y el significado cultural (Monroy et al. 1996).

Valor de uso $=\quad$ Total de entrevistas en que aparece una especie X100 / Total de entrevistas

\section{Elaboración de diccionarios}

Se elaboraron diccionarios en ambos idiomas con la ayuda de miembros de la comunidad que sirvieron de intérpretes parar traducir los nombres del idioma Español a la lengua Emberá.

\section{RESULTADOS Y DISCUSIÓN}

Se registraron e identificaron 81 especies de plantas correspondientes a 38 familias , 69 géneros y 71 especies. De las familias más representativas sobresalen Malvaceae con 8 especies, Arecaceae con 8 especies, Anacardiaceae con 7 especies y Rubiaceae con 5 especies. Entre las especies más representativas se encontraron : Anacardium excelsum, Spondias mombin, Annona muricata, Xylopia serícea, Bactris gasipaes, Elaeis oleifera, Luhea seemannii, Ochroma pyramidale, entre otras. Especies que coinciden en ser especies con muchos usos dentro de estas comunidades (ver Tabla 1).

\begin{tabular}{|l|l|l|}
\hline \multicolumn{2}{|l|}{ TABLA 1. Especies utilizadas por las comunidades de La Bonga y Emberá Cimarrones } \\
\hline FAMILIA & ESPECIE & NOMBRE COMÚN \\
\hline Amaranthaceae & Celosia plumosa & Cresta de gallo \\
\hline \multirow{5}{*}{ Anacardiaceae } & Anacardium excelsum & Espavé \\
\cline { 2 - 3 } & Mangifera indica & Mango \\
\cline { 2 - 3 } & Spondias dulcis & Mangotín \\
\cline { 2 - 3 } & Spondias mombin & Jobo \\
\cline { 2 - 3 } & Tapirira guianensis & Caobilla \\
\hline Annonaceae & Annona muricata & Guanábana \\
\cline { 2 - 3 } & Xylopia sericea & Malagueto \\
\hline Apiaceae & Eryngium foetidum & Culantro \\
\hline Araceae & Colocasia esculenta & Otoe \\
\hline \multirow{5}{*}{ Arecaceae } & Acrocomia aculeata & Corozo \\
\cline { 2 - 3 } & Attalea maripa & Palma real \\
\cline { 2 - 3 } & Bactris gasipaes & Pibá / Pixbae \\
\cline { 2 - 3 } & Cocos nucifera & Palma de cocos \\
\cline { 2 - 3 } & Elaeis oleifera & Palma elaeis \\
\cline { 2 - 3 } & Phytelephas macrocarpa & Tagua \\
\hline Asparagaceae & Cordyline fruticosa & Planta Ti \\
\hline
\end{tabular}




\begin{tabular}{|c|c|c|}
\hline \multirow{3}{*}{ Asteraceae } & Elephantopus mollis & Escobilla \\
\hline & Neurolaena lobata & Contra gavilana \\
\hline & Vernonanthura patens & Lengua de buey \\
\hline \multirow{3}{*}{ Bignoniaceae } & Crescentia cujete & Totumo \\
\hline & Jacaranda copaia & Nazareno \\
\hline & Tabebuia rosea & Guayacán rosado \\
\hline Bixaceae & Bixa orellana & Achiote \\
\hline Burseraceae & Trattinnickia aspera & Caraña \\
\hline \multirow[t]{2}{*}{ Calophyllaceae } & Calophyllum brasiliense & Palo Maria \\
\hline & Mammea americana & Mamey \\
\hline \multirow[t]{2}{*}{ Caricaceae } & Carica papaya & Papaya \\
\hline & Jacaratia spinosa & Papayo de monte \\
\hline Combretaceae & Terminalia oblonga & Amarillo \\
\hline Costaceae & Costus & Caña agría \\
\hline Cyclanthaceae & Carludovica palmata & Jipijapa \\
\hline \multirow[t]{2}{*}{ Euphorbiaceae } & Codiaeum variegatum & Crotón \\
\hline & Manihot esculenta & Yuca \\
\hline \multirow{3}{*}{ Fabaceae } & Cajanus cajan & Guandú \\
\hline & Gliricidia sepium & Mata ratón \\
\hline & Inga edulis & Guaba \\
\hline \multirow[t]{3}{*}{ Lauraceae } & Laurus nobilis & Laurel \\
\hline & Ocotea cernua & Sigua \\
\hline & Persea americana & Aguacate \\
\hline Lecythidaceae & Gustavia superba & Membrillo \\
\hline Malpighiaceae & Byrsonima crassifolia & Nance \\
\hline \multirow{7}{*}{ Malvaceae } & Apeiba tibourbou & Peine de mono \\
\hline & Hibiscus rosa-sinesis & Papo \\
\hline & Luehea seemannii & Guácimo colorado \\
\hline & Ochroma pyramidale & Balso \\
\hline & $\begin{array}{l}\text { Pseudobombax } \\
\text { septenatum }\end{array}$ & Barrigón \\
\hline & Theobroma cacao & Cacao \\
\hline & Herrania purpurea & Bacao (cacao silvestre) \\
\hline Marantaceae & Calathea lutea & Bijao \\
\hline \multirow[b]{2}{*}{ Meliaceae } & Cedrela odorata & Cedro amargo \\
\hline & Swietenia macrophylla & Caobo \\
\hline Moraceae & Ficus insipida & Higuerón \\
\hline Musaceae & Musa $\times$ paradisiaca & Plátano \\
\hline \multirow[t]{2}{*}{ Myrtaceae } & Psidium guajava & Guayaba \\
\hline & Syzygium malaccense & Marañón curazao \\
\hline Pinaceae & Pinus & Pino \\
\hline Piperaceae & Piper reticulatum & Hinojo \\
\hline \multirow[t]{2}{*}{ Poaceae } & Bambudoideae & Bambú \\
\hline & Saccharum officinarum & Caña de azúcar \\
\hline Polygonaceae & Coccoloba tuerckeimii & Teca de montaña \\
\hline Rosaceae & Prunus domestica & Ciruelo \\
\hline \multirow{3}{*}{ Rubiaceae } & Amaioua corymbosa & Madroño \\
\hline & Borojoa patinoi & Borojó \\
\hline & Coffea arabica & Café/ Cafetos \\
\hline
\end{tabular}




\begin{tabular}{|l|l|l|}
\hline & Genipa americana & Jagua \\
\hline \multirow{2}{*}{ Rutaceae } & Citrus sinensis & Naranjo dulce \\
\cline { 2 - 3 } & Zanthoxylum acuminatum & Tachuelo \\
\hline Sapindaceae & Melicoccus bijugatus & Mamón \\
\hline Sapotaceae & Chrysophyllum cainito & Caimito \\
\hline \multirow{3}{*}{ Solanaceae } & Capsicum annuum & Ají \\
\hline & & \\
\hline Urticaceae & Cestrum nocturnum & Dama de noche \\
\hline Fuente: Datos propios (2020). & Guarumo \\
\hline
\end{tabular}

La comunidad Emberá hace uso del recurso vegetal disponible a su alrededor. No hay duda que estas especies vegetales influyen en la calidad de vida de los habitantes de estas comunidades, ya que las mismas son utilizadas en su diario vivir desde su alimentación, salud, vivienda, artesanías, entre otras. Todas las especies reportadas poseen hasta 5 usos. Se identificaron 5 categorías etnobotánicas relevantes: comestible, medicinal, vivienda, maderable, artesanal ( ver Tabla 2 y 3). Estas categorías coinciden con trabajos de Alburquerque et al., 2007 en estudios etnobotánicos con comunidades indígenas.

TABLA 2. Especies según Categorías de Uso. COMUNIDAD LA BONGA

\begin{tabular}{|c|c|c|c|}
\hline ESPECIE & $\begin{array}{l}\text { NOMBRE } \\
\text { COMÚN }\end{array}$ & $\begin{array}{l}\text { NÚMERO } \\
\text { DE USOS }\end{array}$ & CATEGORÍAS DE USO \\
\hline Bambudoideae & Bambú & 5 & Comestible, medicinal, artesanal, ornamental y vivienda. \\
\hline Coffea arabica & Café/ Cafetos & 5 & Comestible, medicinal, artesanal, insecticida y de interés. \\
\hline Genipa americana & Jagua & 5 & Medicinal, artesanal, maderable, insecticida y de interés. \\
\hline Pinus sp. & Pino & 5 & Medicinal, artesanal, ornamental, vivienda y maderable. \\
\hline Melicoccus bijugatus & Mamón & 5 & Comestible, medicinal, vivienda, maderable e insecticida. \\
\hline Chrysophyllum cainito & Caimito & 5 & Comestible, medicinal, artesanal, ornamental y madera. \\
\hline Cedrela odorata & Cedro amargo & 5 & Artesanal, ornamental, vivienda, maderable y de interés. \\
\hline Cocos nucifera & Palma de cocos & 4 & Comestible, medicinal, artesanal y de interés. \\
\hline Calophyllum brasiliense & Palo Maria & 4 & Artesanal, vivienda, maderable y de interés. \\
\hline Mammea americana & Mamey & 4 & Comestible, medicinal, ornamental e insecticida. \\
\hline Gustavia superba & Membrillo & 4 & Comestible, medicinal, ornamental y maderable. \\
\hline Laurus nobilis & Laurel & 4 & Comestible, medicinal, artesanal y ornamental. \\
\hline Hibiscus rosa-sinesis & Papo & 4 & Comestible, medicinal, artesanal y ornamental. \\
\hline
\end{tabular}




\begin{tabular}{|l|l|l|l|}
\hline Calathea lutea & Bijao & 4 & Comestible, artesanal, vivienda y de interés. \\
\hline Fuente: Datos propios (2020).
\end{tabular}

\begin{tabular}{|l|c|c|l|}
\hline \multicolumn{2}{|c|}{ TABLA 3. Especies según categorías de uso GATÚN } \\
\hline ESPECIE & $\begin{array}{l}\text { NOMBRE } \\
\text { COMÚN }\end{array}$ & $\begin{array}{l}\text { NÚMERO } \\
\text { DE USOS }\end{array}$ & CATEGORÍAS DE USO \\
\hline Genipa americana & Jagua & 5 & Medicinal, artesanal, maderable, insecticida y de interés. \\
\hline Cocos nucifera & Palma de cocos & 4 & Comestible, medicinal, artesanal y de interés. \\
\hline Phytelephas macrocarpa & Tagua & 4 & Medicinal, artesanal, vivienda y de interés. \\
\hline Pseudobombax septenatum & Barrigón & 4 & Comestible, artesanal, maderable y de interés. \\
\hline Fuente: Datos propios (2020). & & & \\
\hline
\end{tabular}

En la Comunidad La Bonga ( ver Tabla 4) se pueden observar las especies con mayor significado cultural. Especies muy comunes en los trópicos y algunas que son introducidas de los paleotrópicos, pero que son en su mayoría son especies con uso alimenticio y medicinal. Esta comunidad por ser una comunidad apartada tiene a su disposición especies vegetales que les proveen de alimento y para uso de remedios caseros.

TABLA 4. INDICE DE VALOR DE USO DE LAS ESPECIES VEGETALES DE LA COMUNIDAD LA BONGA

\begin{tabular}{|l|l|l|l|l|}
\hline Especie & Nombre común & Familia & U & IVU \\
\hline Byrsonima crassifolia & Nance & Malpighiaceae & 12 & \\
\hline Cajanus cajan & Guandú & Fabaceae & 12 \\
\hline Calathea lutea & Bijao & Marantaceae & 12 \\
\hline Capsicum annuum & Ají & Solanaceae & 12 \\
\hline Carica papaya & Papaya & Caricaceae & 12 \\
\hline Citrus sinensis & Naranjo dulce & Rutaceae & 12 \\
\hline Chysophyllum cainito & Caimito & Sapotaceae & 12 \\
\hline Cocos nucifera & Palma de cocos & Arecaceae & 12 \\
\hline Coffea arabica & Café/ Cafetos & Rubiaceae & 12 \\
\hline Genipa americana & Jagua & Rubiaceae & 12 \\
\hline
\end{tabular}




\begin{tabular}{|c|c|c|c|c|}
\hline Manihot esculenta & Yuca & Euphorbiaceae & 12 & 100 \\
\hline Mangifera indica & Mango & Anacardiaceae & 12 & \\
\hline Melicoccus bijugatus & Mamón & Sapindaceae & 12 & \\
\hline Musa x paradisiaca & Plátano & Musaceae & 12 & \\
\hline Persea americana & Aguacate & Lauraceae & 12 & \\
\hline Psidium guajava & Guayaba & Myrtaceae & 12 & \\
\hline Saccharum officinarum & Caña de azúcar & Poaceae & 12 & \\
\hline Spondias dulcis & Mangotín & Anacardiaceae & 12 & \\
\hline Syzygium malaccense & Marañón curazao & Myrtaceae & 12 & \\
\hline Annona muricata & Guanábana & Annonaceae & 10 & 83.33 \\
\hline Anacardium excelsum & Espavé & Anacardiaceae & 9 & \multirow{7}{*}{75} \\
\hline Bambudoideae & Bambú & Poaceae & 9 & \\
\hline Bixa orellana & Achiote & Bixaceae & 9 & \\
\hline Cedrela odorata & Cedro amargo & Meliaceae & 9 & \\
\hline Inga edulis & Guaba & Fabaceae & 9 & \\
\hline Swietenia macrophylla & Caobo & Meliaceae & 9 & \\
\hline Theobroma cacao & Cacao & Malvaceae & 9 & \\
\hline Costus sp. & Caña agría & Costaceae & 8 & \multirow{6}{*}{66.6} \\
\hline Eryngium foetidum & Culantro & Apiaceae & 8 & \\
\hline Spondias mombin & Jobo & Anacardiaceae & 8 & \\
\hline Tabebuia rosea & Guayacán rosado & Bignoniaceae & 8 & \\
\hline Zanthoxylum acuminatum & Tachuelo & Rutaceae & 8 & \\
\hline Bactris gasipaes & Pifá / Pixbae & Arecaceae & 7 & \\
\hline Borojoa patinoi & Borojó & Rubiaceae & 7 & \multirow{6}{*}{58.3} \\
\hline Cestrum nocturnum & Dama de noche & Solanaceae & 7 & \\
\hline Colocasia esculenta & Otoe & Araceae & 7 & \\
\hline Ficus insipida & Higuerón & Moraceae & 7 & \\
\hline Gliricidia sepium & Mata ratón & Fabaceae & 7 & \\
\hline Hibiscus rosa-sinesis & Papo & Malvaceae & 7 & \\
\hline
\end{tabular}




\begin{tabular}{|c|c|c|c|}
\hline Mammea americana & Mamey & Calophyllaceae & 7 \\
\hline Pinus & Pino & Pinaceae & 7 \\
\hline Theobroma grandiflorum & $\begin{array}{l}\text { Bacao (cacao } \\
\text { silvestre) }\end{array}$ & Malvaceae & 7 \\
\hline \multicolumn{4}{|c|}{ Fuente: Datos propios (2020). } \\
\hline
\end{tabular}

En la comunidad de Los Cimarrones-Gatún las especies con más significado cultural son las que tienen uso medicinal y artesanal esto se debe a la demanda de usos que se les da a estas especies. Entre ellas tenemos: Cecropia peltata (guarumo) es una especie con uso medicinal y es utilizada para remedios contra la diabetes, asma y para eliminar verrugas, Cocos nucifera (palma de coco) de uso medicinal, comestible, artesanal y de interés autóctono, Genipa americana (jagua)tiene usos medicinales como también artesanal, de la cual la fruta es utilizada para pintar sus cuerpos, Ochroma pyramidale (balso) es una especie que la madera es utilizada para fabricar sus piraguas o canoas, las que utilizan como medio de transporte, Phytelephas macrocarpa (la tagua), Coccoloba tuerckeimii (teca de monte) y Anacardium excelsum (espavé), estas 3 especies también son utilizadas para fabricar sus canoas y viviendas, Trattinnickia aspera ( caraña) es de uso medicinal, esta resina es muy utilizada por la comunidad como ungüento, principalmente para dolores corporales, parches en heridas y golpes (ver Tabla 5).

TABLA 5. INDICE DE VALOR DE USO DE LAS ESPECIES VEGETALES DE LA COMUNIDAD CIMARRONES-GATÚN

\begin{tabular}{|c|c|c|c|c|}
\hline Especie & Nombre común & Familia & $\mathbf{U}$ & IVU \\
\hline Cecropia peltata & Guarumo & Urticaceae & 8 & \multirow{5}{*}{100} \\
\hline Cocos nucifera & Palma de cocos & Arecaceae & 8 & \\
\hline Genipa americana & Jagua & Rubiaceae & 8 & \\
\hline Ochroma pyramidale & Balso & Malvaceae & 8 & \\
\hline Phytelephas macrocarpa & Tagua & Arecaceae & 8 & \\
\hline Coccoloba tuerckeimii & Teca de montaña & Polygonaceae & 7 & 87.5 \\
\hline Anacardium excelsum & Espavé & Anacardiaceae & 6 & \multirow{6}{*}{75} \\
\hline Trattinnickia aspera & Caraña & Burseraceae & 6 & \\
\hline Guazuma ulmifolia & Guácimo & Malvaceae & 6 & \\
\hline Pseudobombax septenatum & Barrigón & Malvaceae & 6 & \\
\hline Spondias mombin & Jobo & Anacardiaceae & 6 & \\
\hline Tabebuia rosea & Roble / Guayacán rosado & Bignoniaceae & 6 & \\
\hline Apeiba tibourbou & Peine de mono & Malvaceae & 5 & \multirow{4}{*}{62.5} \\
\hline Neurolaena lobata & Contra gavilana & Asteraceae & 5 & \\
\hline Vernonanthura patens & Lengua de buey & Asteraceae & 5 & \\
\hline Zanthoxylum acuminatum & Tachuelo & Rutaceae & 5 & \\
\hline Acrocomia aculeata & Corozo & Arecaceae & 4 & \multirow[b]{2}{*}{50} \\
\hline Amaioua corymbosa & Madroño & Rubiaceae & 4 & \\
\hline
\end{tabular}

De acuerdo a las entrevistas realizadas a los moradores de las comunidades (ambas), la parte de la planta mayormente utilizada es la hoja y esto se refleja en que fueron 20 especies mayormente 
mencionadas las que resultaron ser las más utilizadas. Entre ellas tenemos: Mangifera indica, Spondias mombin, Erynggium foetidum, Neurolaena lobata, Crescentia cujete, Bixa orellana, Gliricidia sepium, entre otras. Esto se da porque comúnmente preparan e ingieren las infusiones o té de las hojas para sus remedios medicinales (malestares estomacales, resfríos, entre otros). Otras partes utilizadas de las plantas también son los frutos y semillas a la hora de preparar algún tratamiento natural para alguna dolencia. Este resultado coincide con los estudios de Trujillo y González (2011) en

TABLA 6. PARTES DE LA PLANTA UTILIZADAS MEDICINALMENTE

\begin{tabular}{|c|c|c|}
\hline $\begin{array}{l}\text { PARTES DE LA } \\
\text { PLANTA UTILIZADA }\end{array}$ & $\begin{array}{l}\text { ESPECIES } \\
\text { MENCIONADA }\end{array}$ & NOMBRE \\
\hline Hojas & 20 & $\begin{array}{l}\text { Mango, jobo, guanábana, culantro, contra gavilana, } \\
\text { totumo, achiote, crotón, guandú, mata ratón, , aguacate, } \\
\text { nance, cacao, guayaba, hinojo, naranjo dulce, mamón, } \\
\text { guarumo }\end{array}$ \\
\hline Fruto & 11 & $\begin{array}{l}\text { Corozo, pifá, cocos, totumo, mamey, guaba, guayaba, } \\
\text { borojó, café, jagua, caimito }\end{array}$ \\
\hline Semillas & 7 & $\begin{array}{l}\text { Guanábana, papaya, crotón, guandú, membrillo, cacao, } \\
\text { hinojo. }\end{array}$ \\
\hline Corteza & 5 & Jobo, nazareno, guayacán rosado, crotón, caña de azúcar \\
\hline Raíz & 5 & Jobo, tagua, yuca, marañón curazao, bambú \\
\hline Flor & 3 & Crotón, guandú, papo \\
\hline Pulpa & 2 & Guanábana, totumo \\
\hline Resina & 2 & Caraña, guandú. \\
\hline Toda la planta & 2 & Escobilla, lengua de buey \\
\hline Tallos & 1 & Caña agría \\
\hline Espinas & 1 & Pino \\
\hline Brotes verdes & 1 & Guandú \\
\hline
\end{tabular}

comunidades indígenas Emberá en Colombia (ver Tabla 6 ).

Enfermedades que tratan los Emberá con la vegetación de la comunidad

De las 81 especies registradas, 43 son medicinales, donde la especie Spondias mombin (jobo) resalta como una especie con uso bastante amplio, la misma se puede utilizar para problemas estomacales, digestivos, respiratorios, colesterol, problemas en las vías urinarias, cálculos renales, conjuntivitis y anemia. También se pudo observar que la mayoría de las plantas medicinales son utilizadas para tratar problemas estomacales, digestivos, respiratorios y contra la diabetes ( ver Tabla 7). 


\begin{tabular}{|c|c|c|}
\hline ENFERMEDADES & $\begin{array}{c}\text { ESPECIES } \\
\text { MENCIONADAS }\end{array}$ & PLANTA \\
\hline $\begin{array}{l}\text { Problemas estomacales y } \\
\text { digestivos }\end{array}$ & 12 & $\begin{array}{l}\text { Jobo, tagua, culantro, pifá, yuca, guaba, laurel, } \\
\text { aguacate, hinojo, caña de azúcar, jagua, mamey. }\end{array}$ \\
\hline Problemas respiratorios & 11 & $\begin{array}{l}\text { Jobo, lengua de buey, totumo, guandú, laurel, } \\
\text { aguacate, membrillo, pino, borojó, caimito, } \\
\text { guarumo. }\end{array}$ \\
\hline Diabetes & 10 & $\begin{array}{l}\text { Mango, palma de cocos, contra gavilana, guayacán } \\
\text { rosado, aguacate, cacao, marañón curazao, café, } \\
\text { guarumo. }\end{array}$ \\
\hline $\begin{array}{l}\text { Quemaduras e infecciones en } \\
\text { la piel }\end{array}$ & 6 & $\begin{array}{l}\text { Escobilla, guandú, mata ratón, papo, hinojo, } \\
\text { guarumo. }\end{array}$ \\
\hline $\begin{array}{l}\text { Problemas en las vías } \\
\text { urinarias, renales y uterinos }\end{array}$ & 5 & Jobo, totumo, achiote, caña agría, aguacate \\
\hline Colesterol & 4 & Pibá, palma de cocos, cacao, bambú \\
\hline Parásitos & 4 & Guayacán rosado, papaya, crotón, guayaba \\
\hline Anemia & 4 & Jobo, corozo, pifá, nance \\
\hline Artritis & 2 & Laurel, nance \\
\hline Fiebre & 2 & Contra gavilana, crotón \\
\hline Problemas hepáticos & 2 & Guanábana, crotón \\
\hline Conjuntivitis & 1 & Jobo \\
\hline Presión sanguínea & 1 & Palma de coco \\
\hline Problemas cardiovasculares & 1 & Bambú \\
\hline \multicolumn{3}{|l|}{ Fuente: Datos propios (2020). } \\
\hline
\end{tabular}

Las plantas medicinales para los Emberá son importantes ya que son utilizadas para tratar dolencias y curar enfermedades de forma natural, estas plantas tienen componentes activos que generan determinados efectos en el cuerpo humano. Es importante mencionar que los pueblos indígenas han desarrollado conocimientos sobre las propiedades curativas de algunas plantas que se emplean en el tratamiento de enfermedades parasitarias (amebas, virus o bacterias), problemas estomacales (diarrea, gastritis, falta de apetito etc.), enfermedades respiratorias (asma, bronquitis, entre otras enfermedades). Ese conocimiento de las propiedades curativas de las plantas ha sido heredado de generación en generación y es muy valioso, ya que hoy día el ser humano está volviendo a hacer uso de los compuestos naturales de las plantas para la elaboración de los medicamentos.

Las plantas con uso medicinal poseen un gran rango de usos entre los que tenemos: problemas gástricos, conjuntivitis, resfríos, dolores renales, anemia, vómitos, problemas hepáticos, para reducir colesterol, antiinflamatorios, evitar estreñimiento, entre otras (ver Tabla 8) 
TABLA 8. USOS MEDICINALES DE LAS PLANTAS ESTUDIADAS

\begin{tabular}{|c|c|c|}
\hline ESPEICE & PARTE UTILIZADA & APLICACIÓN \\
\hline Mangifera indica & Hojas & Contra la diabetes \\
\hline Spondias mombin & Corteza, raíz y hojas & $\begin{array}{l}\text { Problemas gástricos, conjuntivitis, resfríos, dolor } \\
\text { renal, anemia, otros. }\end{array}$ \\
\hline Annona muricata & $\begin{array}{l}\text { Semillas, pulpa y } \\
\text { hojas. }\end{array}$ & $\begin{array}{l}\text { Vómitos, problemas hepáticos, curar chinche y } \\
\text { piojos. }\end{array}$ \\
\hline Eryngium foetidum & Hojas & Es antinflamatorio, evita el estreñimiento. \\
\hline Acrocomia aculeata & Fruto & Contra la anemia y debilidad. \\
\hline Bactris gasipaes & Fruto & $\begin{array}{l}\text { Reducir colesterol, problemas digestivos, anemia } \\
\text { y falta de apetito. }\end{array}$ \\
\hline Cocos nucifera & Fruto & Regular presión sanguínea, diabetes y colesterol. \\
\hline $\begin{array}{l}\text { Phytelephas } \\
\text { macrocarpa }\end{array}$ & Raíces & Combatir problemas estomacales. \\
\hline Elephantopus mollis & Toda la planta & $\begin{array}{l}\text { Quemaduras e infecciones de piel, diarrea y } \\
\text { hemorragias intestinales. }\end{array}$ \\
\hline Neurolaena lobata & Hojas & Bajar la fiebre diabetes. \\
\hline Vernonanthura patens & Toda la planta & Aliviar tos, catarros, y limpiar vías respiratorias. \\
\hline Crescentia cujete & $\begin{array}{l}\text { Hojas y pulpa de } \\
\text { frutos }\end{array}$ & $\begin{array}{l}\text { Presión alta, desinflamante, quistes uterinos, } \\
\text { gripe, bronquitis y asma. }\end{array}$ \\
\hline Jacaranda copaia & Hojas y corteza & Tratamiento contra la ameba. \\
\hline Tabebuia rosea & Corteza & Diabetes, paludismo, tifoidea y parásitos. \\
\hline Bixa orellana & Hojas & Regula la función renal. \\
\hline Trattinnickia aspera & Resina & $\begin{array}{l}\text { Para sacar espinas, y curar el mal de ojo de los } \\
\text { niños recién nacidos. }\end{array}$ \\
\hline Mammea americana & Fruto & Eliminar la diarrea y problemas digestivos. \\
\hline Carica papaya & Semillas & $\begin{array}{l}\text { Ayudan al tracto digestivos y protección del } \\
\text { mismo de virus y bacterias. }\end{array}$ \\
\hline Costus & Tallos & $\begin{array}{l}\text { Afecciones de las vías urinarias y eliminación de } \\
\text { cálculos renales. }\end{array}$ \\
\hline Codiaeum variegatum & Toda la planta & $\begin{array}{l}\text { Agrandamiento del hígado, fiebre, como } \\
\text { purgante, y dismenorrea. }\end{array}$ \\
\hline Manihot esculenta & Raíz & $\begin{array}{l}\text { Controla aparato digestivo, gastritis, acidez } \\
\text { estomacal, úlcera o colitis. }\end{array}$ \\
\hline Cajanus cajan & Toda la planta & $\begin{array}{l}\text { Afecciones respiratorias, desinfecta y cicatriza } \\
\text { heridas, sarna y picazón }\end{array}$ \\
\hline Gliricidia sepium & Hojas & Para combatir la sarna y picazón en la piel. \\
\hline Inga edulis & Fruto & $\begin{array}{l}\text { Regular sistema digestivo, estreñimiento y } \\
\text { eliminar toxinas. }\end{array}$ \\
\hline Persea americana & Hojas & $\begin{array}{l}\text { Antioxidante, digestivo, dolor menstrual, tos, } \\
\text { acidez, diabetes. }\end{array}$ \\
\hline Gustavia superba & Semillas & Alivia inflamaciones bronquiales y tos seca. \\
\hline Byrsonima crassifolia & Hojas & Curar dolor de huesos, anemia, fatiga y reuma. \\
\hline Hibiscus rosa-sinesis & Flor & Caspa e irritaciones en la piel. \\
\hline Theobroma cacao & Semillas, hojas & $\begin{array}{l}\text { Alivia estrés, disminuye colesterol, asma, } \\
\text { diabetes. }\end{array}$ \\
\hline Psidium guajava & Hojas y frutos & Utilizada contra la diarrea, y las amebas. \\
\hline Syzygium malaccense & Raíces & Para combatir de la diabetes. \\
\hline Pinus sp. & Espinas & Afecciones respiratorias, gripe y asma. \\
\hline Piper reticulatum & Hojas y semillas & $\begin{array}{l}\text { Malestares estomacales, y heridas externas y } \\
\text { picaduras de insectos. }\end{array}$ \\
\hline
\end{tabular}




\begin{tabular}{|c|c|c|}
\hline Bambudoideae & Raíces & $\begin{array}{l}\text { Disolver el colesterol, protege y regula el } \\
\text { corazón. }\end{array}$ \\
\hline Saccharum officinarum & Corteza interior & Contra la indigestión y el estreñimiento. \\
\hline Borojoa patinoi & Fruto & Afecciones bronquiales. \\
\hline Coffea arabica & Fruto & $\begin{array}{l}\text { Protege contra la diabetes y bueno para el } \\
\text { corazón. }\end{array}$ \\
\hline Genipa americana & Fruto & $\begin{array}{l}\text { Es anti bacteriano, combatir problemas } \\
\text { digestivos. }\end{array}$ \\
\hline Citus sinensis & Hojas & Tratar cólicos estomacales, diarreas y fiebres \\
\hline Melicoccus bijugatus & Hojas & Desinflamar la vejiga e infecciones renales. \\
\hline Chrysophyllum cainito & Fruto & Contra la tos, bronquitis y hemorragias. \\
\hline Cecropia peltata & Hojas & Remedio para diabetes, asma y eliminar verrugas. \\
\hline
\end{tabular}

Los usos etnobotánicos utilizados por las comunidades van desde usos alimenticios, medicinales, para sus viviendas y artesanía y otros instrumentos de uso cotidiano, hasta de interés autóctono.

Los resultados de las entrevistas a los moradores de la Comunidad La Bonga arrojaron un total de 143 usos y la Comunidad Emberá Cimarrones (Gatún) 63 usos. La Comunidad La Bonga cuenta con 169 habitantes y la Comunidad Emberá Cimarrones (Gatún) con 63 habitantes. Se puede decir que hay una relación 1:1 entre la cantidad de habitantes de cada área y el número de usos, lo que indica que cada miembro de estas comunidades es valioso, porque a cada persona sus ancestros le fueron transmitiendo oralmente los diversos usos de las plantas. Se identificaron 8 categorías etnobotánicas: comestible, medicinal, artesanal, ornamental, vivienda, maderable, insecticida e interés autóctono (ver Tabla 8).

\begin{tabular}{|l|c|c|c|c|c|c|c|c|c|}
\hline \multicolumn{9}{|c|}{ TABLA 9. USOS ETNOBOTANCIOS DE LAS ESPECIES POR LA COMUNIDAD } \\
\hline SITIOS & Comestible & Medicinal & Artesanal & Ornamental & Vivienda & Maderable & Insecticida & $\begin{array}{l}\text { Interés } \\
\text { autóctono }\end{array}$ & TOTAL \\
\hline LA BONGA & 36 & 36 & 16 & 13 & 9 & 16 & 5 & 12 & $\mathbf{1 4 3}$ \\
\hline GATUN & 5 & 12 & 10 & 4 & 7 & 15 & 2 & 8 & 63 \\
\hline TOTAL & $\mathbf{4 1}$ & $\mathbf{4 8}$ & $\mathbf{2 6}$ & $\mathbf{1 7}$ & $\mathbf{1 6}$ & $\mathbf{3 1}$ & $\mathbf{7}$ & $\mathbf{2 0}$ & 206 \\
\hline
\end{tabular}

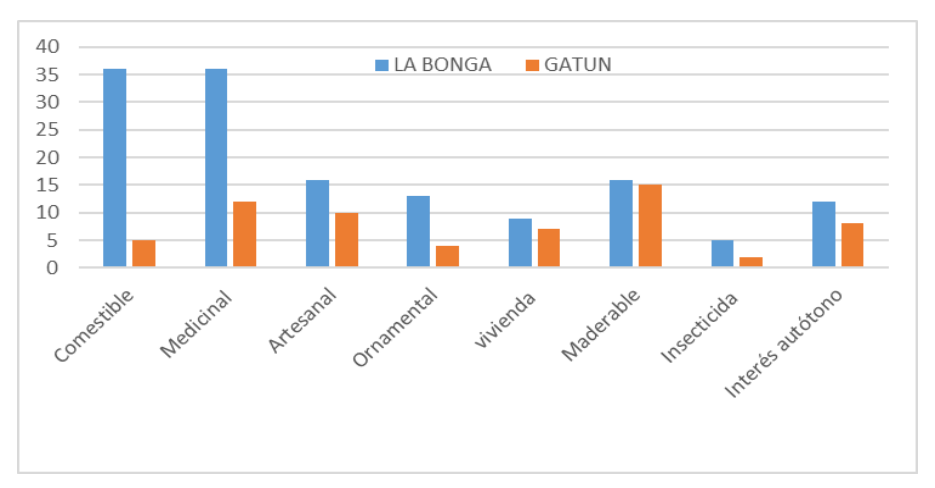




\section{CONCLUSIONES}

Los estudios etnobotánicos son herramientas que permiten directamente la concientización de la conservación de los bosques, ya que todo el conocimiento tradicional que las comunidades indígenas Emberá (San Juan de Pequení y Gatún) le dan a las plantas de su entorno, sobre todo el conocimiento de las especies silvestres está quedando en las personas mayores y corre el riesgo de perderse este conocimiento ancestral, que es heredado de generación en generación por curanderos y demás personas involucradas en el conocimiento de los usos de las plantas, conocimiento valioso, transmitido vía oral y como consecuencia del reemplazo de las especies silvestres medicinales por los fármacos sintéticos, la erosión cultural y la occidentalización de los grupos étnicos se va perdiendo día.

Los pueblos indígenas han reconocido desde hace mucho tiempo la importancia de conservar y gestionar adecuadamente los paisajes forestales intactos en sus tierras, no solo porque satisfacen sus necesidades culturales materiales y no materiales, sino también porque refuerzan y restablecen sus obligaciones tradicionales con la tierra, a pesar de ser el $5 \%$ de la población mundial han sabido valorar a profundidad la importancia de la vegetación que les rodea.

El entorno vegetal juega un papel relevante en la vida de los indígenas Emberá, ya que las plantas de su entorno son consideradas recursos básicos para resolver necesidades vitales como es la alimentación, vivienda, medicina, entre otras.

De acuerdo a los estudios etnográficos realizados, Los Emberá a diferencia de los Guna obtienen del bosque las plantas que son útiles para suplir sus necesidades básicas de alimentación, salud, vivienda, entre otras. Los Gunas trabajan huertos de plantas medicinales, comestibles y demás, cercanos a sus casas. Los Emberá tiene un fuerte arraigo o relación con el bosque, realidad que les exige conservar los bosques de los cuales obtienen los insumos para su vida diaria.

Los estudios etnográficos también reportan que los Emberá son un grupo indígena con mucha apertura a compartir sus remedios medicinales con otros grupos étnicos que no son de su circulo o de su etnia, siendo así se pueden hacer estudios farmacognósticos a profundidad para aislar compuestos activos en plantas que ellos usan, lo que lleva a proyectos innovadores en la farmacología vegetal.

\section{Recomendaciones}

Se considera importante continuar los estudios en las comunidades, organizar capacitaciones institucionales para despertar el interés hacia el cuidado y protección de las plantas medicinales.

Es importante que el investigador etnobotánico mantenga las cualidades éticas y profesionales en la comunidad donde realiza la investigación mostrando respeto por su idiosincrasia, los miembros de la comunidad y creando antecedentes positivos a fin que posteriormente otros investigadores no encuentren inconvenientes 


\section{REFERENCIAS BIBLIOGRÁFICAS}

Aikenvald, A. (2007). "Languages of the Pacific coast of South America", O. Miyaoka, O. Sakiyama, y M. Krauss (eds.) Vanishing Languages of the Pacific: 183-205, Oxford University Press, Oxford, United Kingdom.

Arango, J.U., Iságama M.E. (2012) Flora etnoodontológica de las comunidades indígenas embera del Atrato Medio antioqueño. Rev Fac Odontol Univ Antioq 23(2): 321-333

Catrin Contreras, P. (2015). Cosmovisión indígena y la madre tierra.

Duke, J.A. (1968). Darien ethnobotanical dictionary. Battelle Memorial Institute Columbus Laboratories, U.S. AEC report BM - 171-004, Columbus, Ohio. 131 pp.

FAO-CATIE. (2000). Bibliografía Comentada Cambios en la Cobertura Forestal. Panamá. Agosto 2000.

FAO. (2017). Formas en que los pueblos indígenas ayudan a al mundo a lograr \#HAMBRECERO.

Farnum Castro, F. y V. Murillo Godoy. (2014). Inventario Florístico de Árboles y Arbustos en Fragmentos de Bosques por Presión Antrópica Constante. Revista Colón Ciencias, Tecnología y Negocios 1 (2): 74-90.

Farnum Castro, F. (2014). Estimating Optimal Sample Size For Tree Inventories In Panamanian Rainforests. Revista Centros 3 (1): 11-35.

Gómez, L. , J. Arango , B. Siniguí, M. Domicó, y O. Bailarín (2006) Estudio etnobotánico y nutricional de las principales especies vegetales de uso alimentario en territorios de las comunidades Emberá de selva de Pavarandó y Chuscal- Tuguridó (Dabeiba Occidente de Antioquia). Universidad Nacional de Colombia Medellín, Colombia Revista Gestión y Ambiente, . 9 (1) : 4964

INEC. Censo de Población y Vivienda. (2010). Lugares Poblados de la República. Dirección de Estadística y Censo. Panamá.

Jansasoy G. (2019). Emberás y Wounaan en el corazón del Darién. Panamá.

Moreno, M. (2009). Estudio etnobotánico, propagación y desarrollo en vivero de "Chilcague" (2001) (A Gray) Blake. [Tesis], Facultad de Agrobiología Presidente Juárez, Universidad Michoacana de San Nicolás de Hidalgo, Michoacán, México.

Rivas Ríos, F. (2015). Comarcas de Panamá. 2016. Cuencas hidrográficas de Panamá. Panamá.

Runk, J.V. (2001).Wounaan and Emberá use and management of the fiber palm Astrocaryum standleyanum (Arecaceae) for basketry in eastern Panamá. Econ Bot 55: 72-82 https://doi.org/10.1007/BF02864547

Tossi, J.A. (1971). Inventariación y demostraciones forestales de Panamá, Zonas de Vida.

Sierra Marín de Vergara, Z. (2019). ¿Qué se está haciendo para proteger la cuenca hidrográfica del Canal de Panamá?

Ucha, F. (2013). en definición ABC. 
Vidal Berrío, L. (2019). La conservación de la cuenca, prioridad de la ACP. El capital financiero. Panamá. 